\title{
Fazer-se ouvir, fazer-se entender - atuação política interétnica da COICA nas negociações sobre o clima com a proposta de REDD+ Indígena Amazônico
}

\author{
Isabel Mesquita \\ Instituto de Pesquisa Ambiental da Amazônia - IPAM \\ e-mail: bel.mesquita@gmail.com
}

\begin{abstract}
Resumo
O artigo analisa como uma organização indígena pluritétnica (a Coordinadora de las Organizaciones Indígenas de la Cuenca Amazónica - COICA) atua nas negociações internacionais do clima e faz-se ouvir em espaços políticos regidos por regras e lógicas não-indígenas, nos quais observam-se limitações significativas para o estabelecimento de um diálogo interétnico efetivo. Para realizar esta análise, foi feita uma pesquisa entre 2013 e 2015 a partir de documentos, revisão bibliográfica e trabalho de campo em reuniões da COICA e da Conferência das Nações Unidas sobre as Mudanças Climáticas (COP). O exemplo apresentado neste artigo é o da proposta de "REDD+ Indígena Amazônico" da COICA. Os representantes indígenas que participam das COP realizam um trabalho de tradução e mediação de noções de suas cosmovisões e outras visões de mundo nãoindígenas, a fim de comunicar de maneira inteligível as mensagens que querem transmitir em espaços que não foram construídos para acolher tal diversidade. Ao fazer isso, estes indígenas são capazes de influenciar processos de tomada de decisão e garantir direitos e benefícios para os povos que representam.
\end{abstract}

Palavras-chave: mudanças climáticas, organizações indígenas, REDD+, diálogo interétnico.

\begin{abstract}
This article analyses how a pluriethnical indigenous organization (Coordinadora de las Organizaciones Indígenas de la Cuenca Amazónica - COICA) acts in the international climate change negotiations sphere and make their voice heard in political arenas where non-indigenous rules and logical prevales and despite the limitations to stablish effective interethnical dialogues. For this purpose, the research conducted between 2013 and 2015 includes document and bibliographic review, as well as fieldwork in COICA's meetings and United Nations Climate Change Conference (COP). The example presented in the article is COICA's "Amazonian Indigenous REDD+" proposal. Indigenous representatives who attend the COP translate and mediate notions from their cosmovisions and non-indigenous worldview, in order to make their messages intelligible in such arenas, which aren't built to accept such diversity. By doing so, they are able to influence decision-making processes and guaranteeing rights and benefits to indigenous peoples they represent.
\end{abstract}

Keywords: climate change, indigenous organizations, REDD+, interethnic dialogue. 


\section{Introdução}

O presente artigo trata de como a rede de organizações indígenas denominada a Coordinadora de las Organizaciones Indígenas de la Cuenca Amazónica (COICA) se comunica e atua politicamente, e como tornam suas reivindicações compreensíveis para diversos segmentos de não-indígenas a partir da proposta própria "REDD+ Indígena Amazônico (RIA)" apresentada em negociações sobre o clima. Trata-se, portanto, de olhar para como esta organização indígena transnacional se faz ouvir em espaços internacionais de tomada de decisão, no caso, as Conferências das Partes da ONU (COP). E compreender as maneiras da COICA se colocar nas COP a partir das limitações para o estabelecimento de diálogos interétnicos.

Entende-se aqui a configuração da COICA enquanto sujeito político indígena cuja identidade que se constrói de maneira dispersa (Marcus 1991), respondendo a realidades sociais que articulam diferentes escalas (local, regional, e global). Assim, pesquisa que originou este artigo partiu de uma concepção de campo que não é baseada em uma localidade específica, mas multilocal. Neste caso, fóruns e reuniões internacionais compostos por setores diversos - como organizações indígenas, Organizações NãoGovernamentais (ONGs), empresas e governos -, são espaços privilegiados de observação, pois nestes são tomadas decisões, estabelecem-se vínculos e parcerias, obtém-se recursos e por vezes configuram-se lideranças e diretrizes políticas (Valente, 2010). Por estas razões, a análise da conjuntura e circunstâncias locais, regionais ou mesmo nacionais não são suficientes para explicar como se configuram as estratégias e ações da COICA - isto vale também para a atuação de outras organizações indígenas de configuração similar, como o International Indian Treaty Council e o Indigenous Peoples' International Centre for Policy Research and Education - Tebtebba ${ }^{1}$.

Para compreender a construção da proposta de RIA, desenvolvida entre 2011 e 2015, apreender este campo multilocalizado e sua influência sobre a atuação e identidade da COICA é importante descrever o histórico da organização e reconstituir sua trajetória institucional e conformação enquanto sujeito político, atentando para a constituição de suas propostas

\footnotetext{
${ }^{1}$ O International Indian Treaty Council (IITC) foi fundado nos Estados Unidos em 1974 no contexto de formação do movimento indígena estado-unidense, mas que reúne lideranças da América do Norte, do Sul e Caribe; Tebtebba é uma organização indígena fundada em 1996 e sediada nas Filipinas, que promove os direitos dos povos indígenas situados em todas as partes do mundo. Ambas as organizações tiveram participação ativa na elaboração da Declaração dos Direitos dos Povos Indígenas (2007) e em fóruns da ONU.
} 
e pautas ao longo da sua existência e para os protagonistas indígenas que desempenharam papéis de destaque nesses processos.

A inserção neste campo, de debates e negociações sobre clima, me possibilitou efetuar uma pesquisa que teve início em 2012, quando fui trabalhar em uma ONG que desenvolvia ações sobre mudanças climáticas em parceria com a COICA. Assim, entre 2012 e 2015, participei ativamente de reuniões com representantes da COICA, de ONGs e de governos. Nessa dinâmica consegui uma interlocução direta com diversos sujeitos envolvidos na construção da proposta de RIA e nas negociações sobre clima. Foi precisamente por ocupar este lugar que algumas perguntas me instigaram a desenvolver uma pesquisa visando entender os significados para sujeitos diversos.

Apesar das várias possibilidades, o foco da pesquisa recaiu sobre compreender como a proposta de RIA enunciada pela COICA em fóruns internacionais era apreendida e interpretada pelos interlocutores nãoindígenas da organização. A metodologia de pesquisa utilizada para abordar o tema consistiu nas seguintes etapas: 1) mapeamento de organizações indígenas transnacionais que participam das negociações sobre o clima e de iniciativas da COICA no âmbito internacional (documentos e registros submetidos e apresentados na UNFCCC por organizações indígenas); 2) levantamento e descrição da trajetória da COICA, com ênfase nos seus posicionamentos em temas relacionados a meio ambiente e mudanças climáticas (a partir de revisão bibliográfica e documentos da COICA); 3) descrição dos sujeitos envolvidos e principais aspectos (fóruns, decisões e documentos) das negociações de mudanças climáticas, que informaram a elaboração da proposta de RIA, a partir da minha própria inserção neste campo ${ }^{2}$ e de revisão bibliográfica.

Em primeiro lugar, cabe colocar que a dimensão do diálogo interétnico analisada refere-se ao diálogo entre indígenas e não-indígenas. Assume-se aqui que o contraste entre esses sujeitos é constitutivo destes dois grandes grupos, ainda que existam diversos grupos étnicos dentro das categorias "indígena" e "não-indígena". Os grupos étnicos, de acordo com Cardoso de Oliveira (1976), definem-se por características comuns relacionadas a fatores biológicos, valores, práticas culturais e pela identificação entre membros (externos e internos). Entretanto, a identidade étnica é

\footnotetext{
${ }^{2} O$ trabalho de campo consistiu no acompanhamento de diversas reuniões entre 2012 e 2015, das quais destacamse: o "Taller Regional Cambio Climático, REDD+ y REDD+ Indígena Amazónico" promovido pela COICA em julho de 2013, na Guiana Francesa; o o "10 Encontro REDD+ Indígena Amazônico", também promovido pela COICA em maio de 2014, no Acre e a $20^{\text {a }}$ Conferência das Partes da ONU (COP20) em dezembro de 2014, no Peru.
} 
constrastiva, ou seja, só existe a partir do momento em que é possível identificar um grupo étnico em oposição a outro.

Assim, a noção de indígena é compreendida aqui como resultado de um fenômeno histórico cuja existência e sentido estão diretamente relacionados ao contexto colonial, no qual era preciso denominar, de maneira homogênea, os povos a serem "conquistados" na América (Bonfil Batalla 1972). "Índio" e "indígena" são categorias supraétnicas que não levam em conta as especificidades dos grupos étnicos aí agrupados, e sim a identidade étnica marcada pela diferenciação entre indígena e nãoindígena, tomando como referência ponto em que suas histórias se encontram: a partir do momento em que entram em contato com povos colonizadores e passam a ocupar uma posição comum de subordinação. Hoje, a utilização do termo povos indígenas é mantida apesar de passados séculos do momento histórico em que o termo foi concebido. Isto porque grande parte dos povos indígenas existente hoje construiu ou adaptou seus padrões de vida a partir da relação com lógicas de conquista e colonização; é a partir deste fato histórico - a colonização - que as trajetórias de centenas de etnias são reunidas e passam a ser consideradas como povos indígenas.

Para Ronald Niezen (2003), os que se denominam povos indígenas compartilham atualmente similaridades significativas em suas experiências coloniais e pós-coloniais, tais como perda de terra e de meios de subsistência, quebra de tratos e imposição de políticas assimilacionistas destrutivas em termos psicológicos e sociais. Portanto, se de um lado entende-se aqui a diversidade do conceito "indígena" e sua limitação para dar conta da diversidade de etnias que são abarcadas por este conceito (tornando-o, em certa medida, uma ficção), este é o ponto de partida para analisar de que modo têm lugar interações e diálogos entre povos que se situaram em posições marcadamente distintas durante e após o período colonial.

Além da identificação desta "essência" que constitui base comum aos povos indígenas - e de seus discursos -, outros fatores caracterizam o que se pode chamar de movimento indígena ${ }^{3}$, tais como: a associação entre reivindicações políticas e identidade; a construção de diálogo a partir dos termos manejados pelos interlocutores-alvo - sendo estes, usualmente, Estados nacionais; e a apropriação e ressignificação de discursos e estratégias utilizados por sujeitos não-indígenas para fortalecer das pautas e organizações indígenas (Bello 2004). A ação coletiva dos povos indígenas

\footnotetext{
${ }^{3}$ Tratamos aqui do movimento indígena no singular, assumindo que esta é uma categoria estratégica de unificação de pautas que fortalece politicamente as reivindicações indígenas (ver Baniwa 2007 e Mesquita 2016).
} 
é ancorada na defesa de sua identidade plural; dessa maneira, a atuação do movimento indígena é intrinsecamente ligada à luta pelo reconhecimento da diversidade dos grupos étnicos que o constituem. Por essa razão, considera-se que a base do movimento indígena é identitária, tendo como especificidade e potência seu caráter pluriétnico.

É interessante observar dois aspectos da construção da identidade indígena: o primeiro é sua construção a partir de dois tipos de identidades aparentemente paradoxais - uma mais genérica, indígena, comum a diversos povos de todo o mundo; e outra particular, vinculada ao pertencimento a uma família, a uma comunidade, a um território e a todo conhecimento a este associado. O segundo aspecto a se destacar é a característica processual desta identidade, que se constrói e fortalece à medida em que é reconhecida por grupos externos (não-indígenas); é, neste sentido, passível de grande diversidade e aberta a contínuas transformações e adaptações. A identidade indígena, assumida por grupos e indivíduos em situações concretas, é uma identidade em processo. Gross (2000) descreve como, na Colômbia, ameaças e pressões territoriais levam populações indígenas a buscarem suas origens étnicas e reivindicarem seus direitos. No caso colombiano, é nítido que o reconhecimento oficial dos direitos de povos indígenas assinalado pela Constituição de 1991 fortalece a mobilização indígena e a definição da identidade étnica de grupos (como é o caso dos Kankaumo - ver Gros 2000). É nesse sentido que a identidade e os discursos sobre identidade são importantes "armas" utilizadas pelos povos indígenas na defesa de seus direitos na guerra contemporânea do mundo globalizado.

O movimento indígena alcança proporções mundiais por meio da mobilização de redes não-governamentais transnacionais e pela articulação à agenda ambientalista (Brysk 1996). Enquanto a questão ambiental começa a ganhar espaço nas discussões internacionais a partir da década de 1970 (vide a publicação de "Os Limites do Crescimento" Meadows et al., 1972), os povos indígenas são associados a estas pautas a partir da década de 1980. A identificação entre povos indígenas e meio ambiente é resultado de uma interpretação não-indígena da relação entre povos indígenas e os lugares que habitam, vista como uma relação harmônica. Esta interpretação, entretanto, está longe de apreender os termos em que a relação entre grupos étnicos diversos e seus lugares de origem se dá, pois partimos de noções não-indígenas (como "natureza", "preservação" e mesmo a de "indígenas") para estabelecer essa relação categorias que, de início, separam meio ambiente dos seres humanos, diferentemente de cosmologias indígenas diversas que podem apresentar 
entendimentos e categorias bastante distintos - tratam-se de diferenças ontológicas ${ }^{4}$, cuja tradução resumida à identificação de indígenas enquanto "nativos ecológicos" (Ulloa 2004) é bastante superficial. Apesar dos limites dessa tradução, a imagem de "nativo ecológico" ou guardião da natureza é mobilizada tanto por indígenas quanto por seus apoiadores não-indígenas, pois a partir dessa imagem esses grupos étnicos alcançam proeminência política no mundo não-indígena, em um nicho específico - o ambientalista. Existe, contudo, um risco na mobilização dessa imagem de povos indígenas como guardiões da floresta, tendo em vista as diferentes concepções sobre povos indígenas que são mobilizadas pelos não-indígenas a partir destes discursos. Recorrer a esta identificação pode acionar tanto o imaginário que associa povos indígenas ao exotismo e ao "bom selvagem", quanto à ideia oposta de não-civilizado e de "atrasado" (Brysk 1996). Entretanto, essa "performance de indianidade" (Graham 2002) contextualizada (operada em determinados espaços em que se enunciam os discursos indígenas) é o ponto de partida para a aceitação da alteridade étnica dos povos indígenas por seus interlocutores não-indígenas, garantindo, assim, legitimidade aos enunciadores indígenas.

Ao analisar a forma de atuação da COICA nas negociações sobre clima, é possível observar como seu discurso é construído a partir de pontos de convergência entre pautas de reivindicação indígena e ideias enunciadas não-indígenas ambientalistas, tornando-se evidente os esforços de tradução tanto dessa organização indígena quanto de seus apoiadores nãoindígenas. Trata-se de compreender como as formas de incidência política e reivindicações indígenas remetem a outras visões de mundo para fazerse ouvir, e como estas reivindicações são associadas a visões de mundo de grupos não-indígenas para ganharem impulso quando projetadas de maneira conjunta.

\section{Criação da COICA e inserção no ambientalismo}

Entre as décadas de 1960 e 1970 foram criadas organizações indígenas regionais amazônicas (Peru, Equador, Brasil, Bolívia), que reúnem diversas etnias em torno de pautas comuns - direito ao território (frente a invasões e outras ameaças), saúde, educação e valorização da cultura indígena ${ }^{5}$. Paralelamente, a discussão sobre indigenismo vai adquirindo espaço crescente em fóruns e agências internacionais; no mesmo período (19601970), a atuação de antropólogos junto aos povos indígenas amazônicos e a

\footnotetext{
${ }^{4}$ Ver mais em De La Cadena \& Legoas (2014).

${ }^{5}$ Para uma descrição mais detalhada sobre o processo de formação de organizações indígenas regionais, ver Duval (2014) e Bicalho (2010).
} 
formação de organizações de países da Europa, Canadá e Estados Unidos ${ }^{6}$, que lhes dão apoio, trazem visibilidade mundial para a questão indígena dos países da América do Sul, culminando com a Conferência de Barbados (1971). Este impulso é fundamental para a criação e manutenção de organizações regionais nos países amazônicos.

A COICA foi fundada em 1984 na cidade de Lima, Peru, no primeiro Congresso de Organizações Indígenas da Bacia Amazônica, que reuniu cinco organizações regionais indígenas: Asociación Interétnica de Desarrollo de la Selva Peruana (AIDESEP, Peru), Central de Pueblos y Comunidades Indígenas del Oriente Boliviano (CIDOB, Bolívia), Confederación de Nacionalidades Indígenas de la Amazonia Ecuatoriana (CONFENIAE, Equador), Organización Nacional Indígena de Colombia (ONIC, Colômbia) e União das Nações Indígenas (UNI, Brasil). Entre 1992 e 1993, outras quatro organizações indígenas somaram-se à COICA - Consejo Nacional Indio de Venezuela (CONIVE, Venezuela), Organisatie van Inheemsen in Suriname (OIS, Suriname), Amerindian Peoples Association of Guyana (APA, Guiana Inglesa) e Fédération des Organisations Autochtones de Guyane (FOAG, Guiana Francesa).

Entre 1994 e 1995 algumas organizações - UNI e ONIC - deixaram a COICA por razões diversas, dando lugar a outras organizações indígenas destes países: Coordenação das Organizações Indígenas da Amazônia Brasileira (COIAB) e a Organización de Pueblos Indígenas de la Amazonia Colombiana (OPIAC), que se tornou membro da COICA no lugar da ONIC. A formação da COICA acontece após alguns encontros entre organizações indígenas amazônicas em resposta à assinatura do Tratado de Cooperação Amazônica ${ }^{7}$, pela percepção dos impactos que este traria aos povos indígenas da região.

O intuito da constituição da COICA era criar uma organização representativa dos povos indígenas amazônicos e unificar suas vozes em defesa dos direitos dos povos indígenas para atuar em esfera internacional, a partir das pautas comuns dos povos da região (Smith 1996). A COICA seria, então, uma aliança de organizações indígenas para tratar de temas transnacionais, em resposta às iniciativas igualmente transnacionais de intervenção territorial por parte de Estados e empresas. Por isso e para isso, a COICA foi pensada como uma organização que participaria e executaria

\footnotetext{
${ }^{6}$ Como International Work Group for Indigenous Affairs (IWGIA), Survival International e Cultural Survival.

${ }^{7}$ O Tratado de Cooperação Amazônica é assinado por sete países amazônicos em 1978 e entra em vigor com a ratificação da Venezuela em 1980.

${ }^{8}$ Smith (1996) é um dos poucos autores que reconstitui a história dos primeiros anos da COICA, desde a formação de federações étnicas peruanas até a Assembleia Geral da COICA de 1992.
} 
ações internacionais a partir do consenso de suas organizações membro. Além disso, a COICA contou com apoiadores da cooperação internacional desde os seus primeiros anos, destacando-se entre outras entidades internacionais a Agência de Cooperação Técnica Alemã (GIZ), a Fundação Ford e a OXFAM, que viabilizaram financeiramente a instituição e manutenção da COICA.

A estrutura de coordenação de COICA é composta pela Coordenação Geral (Coordenador e Vice-Coordenador), por um Conselho Diretivo (composto por um representante de cada uma das nove organizações membro da COICA, responsáveis pela elaboração de políticas de longo prazo e acompanhar as defendias pelos coordenadores eleitos) e por coordenadores de áreas temáticas (que também são representantes das organizações membro da COICA). Os representantes indígenas que ocupam estes cargos devem ser necessariamente indígenas e parte das organizações membro da COICA - sendo, geralmente, da coordenação destas organizações - e são eleitos para os cargos de Coordenação e Vice-Coordenação Geral em assembleias da COICA, que são realizadas de quatro em quatro anos ${ }^{9}$.

Entre 1989 e 1990, a COICA começa a pautar a necessidade de integrar a questão indígena à agenda ambientalista. No contexto de crescentes intervenções na região amazônica, a proposta da COICA é construir uma aliança com ambientalistas em defesa da Amazônia, colocando a necessidade de se construir uma agenda de conservação da Amazônia que leve em conta o papel dos povos indígenas para tal ${ }^{10}$. Esta foi uma resposta à ideia conservacionista de parques nacionais, difundida especialmente nos Estados Unidos; ao mesmo tempo, a noção de "índio ecológico" - sempre presente no discurso da COICA - vai se consolidando ao longo de sua trajetória e da de outros aliados. A partir desse momento, o discurso da COICA passa a ser pautado pela mensagem de que o modo de vida dos povos indígenas é chave para a proteção da floresta amazônica. Paralelamente, grandes ONGs como World Wildlife Fund(WWF) e The Nature Conservancy passaram a redirecionar suas agendas de maneira a incluir povos tradicionais, reconhecendo em documentos e declarações a importância

\footnotetext{
${ }^{9}$ Há graves problemas de comunicação na COICA, tanto entre os coordenadores das organizações membro, quanto entre estas organizações e suas bases, que deveriam ser representadas por estas na COICA. Estes problemas, ainda presentes, são identificados já nos primeiros anos da COICA e descritos por Smith (1996).

${ }^{10}$ Destacam-se aqui o documento Two Agendas on Amazon Development (COICA 1989), no qual são apresentadas diretrizes para um modelo de desenvolvimento da Amazônia que leve em consideração os povos indígenas e seus direitos; e a Declaração de Iquitos (1990), que atesta a aliança entre povos indígenas e ambientalistas em prol da conservação da Amazônia.
} 
dos povos indígenas e de seus direitos ${ }^{11}$. Dessa maneira, a COICA passa a desenvolver projetos em conjunto com organizações ambientalistas.

Além de influenciar a agenda ambientalista, a COICA participou da revisão do Convenio 169 da OIT e trouxe visibilidade internacional para os povos indígenas amazônicos ${ }^{12}$, articulando uma rede de apoio (estadounidense e europeia) que impulsionou a presença da COICA em fóruns internacionais diversos. Como conquistas, podemos citar a política do Banco Mundial relacionada a povos indígenas definida na Diretiva Operativa 4.20 de $1991^{13}$ - após diálogos entre o então presidente do Banco Mundial, Barber Conable, e o presidente da COICA, Evaristo Nugkuag (Smith 1996) - e o cancelamento da patente de uma espécie de ayahuasca em 2003 (Greene 2006), planta utilizada por diversos povos amazônicos para medicina e rituais. Progressivamente, a COICA passa a participar de maneira contínua dos fóruns sobre povos indígenas e direitos humanos da ONU, das Conferências sobre Meio Ambiente, sobre Biodiversidade e sobre Clima. Entre 1996 e 2001 há um esforço exitoso da COICA em sua participação na Convenção de Diversidade Biológica (CDB) para a construção do reconhecimento do Fórum Indígena Internacional sobre Biodiversidade e na contribuição da COICA, que resulta na criação de um Grupo de Trabalho sobre conhecimentos tradicionais no âmbito desta ${ }^{14}$.

\section{As negociações sobre clima e a participação indígena}

Segundo a definição da ONU (1992), "mudanças climáticas" são as alterações do clima observadas ao longo de determinado período, sendo estes fenômenos resultantes das interações entre a atmosfera, os oceanos, o calor e outros fenômenos naturais. Foi apenas em 2007, com a publicação do quarto relatório do Painel Intergovernamental de Mudanças Climáticas (IPCC na sigla em inglês, de Intergovernmental Panel on Climate Change), que se comprovou cientificamente a relação entre mudanças climáticas e a ação humana, sendo estas uma consequência do aumento de gases de efeito estufa na atmosfera (IPCC 2007). A concentração de gases de efeito estufa, como dióxido de carbono $\left(\mathrm{CO}_{2}\right)$, metano e óxido nitroso, aumenta a partir de 1750 (IPCC 2007) e é associada principalmente à queima de combustíveis fósseis, que liberam $\mathrm{CO}_{2}$ na atmosfera e às mudanças de uso do solo (por

\footnotetext{
${ }^{11}$ Indicador dessa mudança é o documento produzido pela WWF em 1996, Principles and Guidelines on Indigenous and Traditional Peoples and Protected Area: Joint Policy Statement, que reconhece explicitamente o papel e conhecimento dos povos indígenas sobre seus territórios.

${ }^{12}$ Em 1986, o então presidente da COICA, Evaristo Nugkuag, recebe o prêmio Right Livelihood por sua atuação à frente da organização.

${ }^{13}$ Substituída em 2005 pela Política Operacional (OP) e Procedimentos do Banco (BP) 4.10.

${ }^{14}$ Há um paralelo interessante entre a atuação da COICA na CDB e na COP. Ver Mesquita (2016).
} 
exemplo, desmatamento e conversão de áreas de floresta em áreas agrícolas e pastagens).

Até meados da década de 1990, a agenda das mudanças climáticas esteve essencialmente vinculada à agenda ambiental. Na Conferência das Nações Unidas sobre o Meio Ambiente e Desenvolvimento (ECO 92), é elaborada a Convenção-Quadro das Nações Unidas sobre Mudanças Climáticas (UNFCCC, sigla em inglês para United Nations Framework Convention on Climate Change). A UNFCCC é um tratado internacional cujo objetivo principal é estabilizar a concentração de gases de efeito estufa na atmosfera a um nível que assegure a segurança alimentar humana e a adaptação dos ecossistemas.

O tratado estabelece blocos de países, diferenciando-os entre países que mais contribuíram historicamente para as emissões globais de gases de efeito estufa (ao todo, 40 países majoritariamente da União Europeia, América do Norte e Rússia, considerados "industrializados") e os países que menos contribuíram para estas emissões (considerados "em desenvolvimento"). A Convenção ainda designa a Conferência das Partes (COP) como instância para acompanhamento da discussão e implementação de ações que visem alcançar os objetivos da UNFCCC. A UNFCCC entra em vigor em 1994, assinada por 195 países, e a primeira COP ocorre em 1995, sendo realizada anualmente a partir de então, como espaço oficial para a negociação e a tomada de decisões relacionadas à questão climática global. Nestas Conferências, são realizadas paralelamente reuniões de representantes do Estado, grupos de trabalho e corpos técnicos definidos pela UNFCCC ao longo de duas semanas; ocorrem, ainda, eventos organizados pela sociedade civil e pela imprensa (side-events e conferências de imprensa). A participação da sociedade civil nas COP depende de credenciamento prévio, requerido como representante de organizações da sociedade civil ou como parte da delegação oficial de um país. Há uma diferença importante entre o tipo de registro, pois, sendo parte da delegação oficial de um país, recebe-se o registro como "Parte", ao passo que representantes da sociedade civil são registrados como "Observador": os Observadores podem acompanhar apenas as plenárias, side-events e conferências de imprensa dentro do espaço oficial; já as Partes podem acompanhar também as negociações e reuniões dos corpos técnicos e grupos, mas sem direito a fala (restrita nestes espaços apenas para os representantes do governo nas Partes).

A UNFCCC permite a organizações da sociedade civil e organizações intergovernamentais o credenciamento para participar da COP sob o status de "Observador". Porém um indivíduo pode solicitar ao órgão competente 
de seu país (no caso do Brasil, o Ministério de Relações Exteriores) para fazer parte da delegação nacional, cabendo a cada país definir critérios para a aceitação de indivíduos como parte de suas delegações nacionais. Assim, alguns indígenas participam das COP como parte de delegações oficiais, assumindo o status de "Parte", e outros se credenciam por organizações indígenas ou ONGs, com o status de "Observadores". Considerando a quantidade de reuniões e as restrições de acesso e de fala dos Observadores em cada espaço, existe quase uma cisão no espaço oficial do evento: os representantes oficiais das Partes concentram-se nas negociações, reuniões fechadas e plenárias; e a sociedade civil concentra-se nos sideevents, conferências de imprensa e plenárias (a depender do tema e da possibilidade de intervenção, participam de outros espaços e de plenárias específicas). Assim, as COP são espaços que possibilitam uma ainda restrita participação indígena, na medida em que sua possibilidade de incidência (possibilidade de fala) no espaço oficial é circunscrita.

Representantes indígenas participam pela primeira vez de uma COP em 1998 (COP4) e no ano seguinte é realizado o primeiro Forum Internacional Indígena sobre Mudanças Climáticas (International Indigenous Forum on Climate Change), espaço de articulação das organizações indígenas durante as COP para a construção de posicionamentos e estratégias de ação (lobby, manifestações e participação em determinados eventos dentro e fora do espaço oficial da COP durante o período da reunião). A intervenção indígena nas COP é marcada pela realização de conferências de imprensa e sideevents, que trazem visibilidade a um público mais amplo, e a falas em plenárias pontuais, com abertura para contribuições da sociedade civil. Paralelamente, os representantes indígenas articulam diversas reuniões privadas com representantes de governo e não-governamentais, sendo este espaço importante para a articulação e apresentação de agendas das organizações indígenas.

Powless (2012) destaca a diferença entre o posicionamento indígena na UNFCCC em relação ao de outros atores ali presentes: primeiro, por reivindicarem ações ambiciosas para redução imediata de emissão de gases de efeito estufa, criticando "falsas soluções" propostas por empresas e governos; segundo, por identificarem os impactos das atividades que afetam tanto clima quanto povos indígenas (industriais, agropecuárias, matriz energética) como resultado de processos coloniais e do sistema econômico vigente que devem ser combatidos, abordando a dimensão espiritual e não-material da relação entre seres humanos e natureza.

Entretanto, os representantes indígenas que participam desta discussão sobre clima ganham força neste debate a partir dos pontos em comum 
enunciados em seus discursos com o de outros sujeitos: de um lado, as manifestações indígenas por seus direitos e integridade territorial se aproximam das reivindicações de grupos ambientalistas; de outro, das de chefes de Estado de países da América do Sul que colocam as populações originárias de seus países para questionar desigualdades nas relações internacionais entre Estados e modelos de ação e desenvolvimento (bem ilustrado pelo posicionamento dos governos boliviano, equatoriano e venezuelano às vésperas da Conferência do Clima de 2015, enunciando a defesa da Mãe Terra - Pachamama - para cobrar responsabilidade dos países desenvolvidos).

Cabe ressaltar o esforço de promover a incidência indígena neste espaço, considerando a necessidade de garantir transporte, acomodação, alimentação, mas também o trabalho de anos de formação para garantir a participação informada de representantes indígenas em espaços de discussão técnica e política sobre um tema complexo como o de mudanças climáticas. Além disso, cabe colocar a questão dos idiomas falados neste evento; existem espaços (side-events, conferências de imprensa e plenárias) em que a tradução é oferecida para as línguas oficiais da ONU (inglês, francês, espanhol, árabe, russo e chinês); porém há espaços mais restritos de negociação em que não há tradução e exige-se um idioma comum (inglês), o que dificulta ainda mais a participação de indígenas que já tem como segunda língua o idioma oficial de seus países de origem.

\section{Diálogo interétnico e como fazer-se ouvir}

Para o estabelecimento de um diálogo efetivo (ou seja, que possibilite a troca e o entendimento ético entre as partes), é necessário que este conte com o entendimento e o consenso entre os participantes sobre normas e regras sobre as quais o diálogo se estabelecerá. Este consenso só pode ser construído a partir do amplo entendimento de todas as partes sobre os termos em que as regras são discutidas e definidas. Quando pensamos em um diálogo interétnico, ou seja, entre interlocutores que não compartilham dos mesmos pressupostos em relação a visões de mundo, normas e regras, é necessário um esforço ainda maior para alcançar a ética mínima que possibilite um diálogo a partir do estabelecimento de um acordo sobre normas e regras entre as partes, considerando que não compartilham um horizonte semântico comum.

Segundo Roberto Cardoso de Oliveira (2000), a ética discursiva é premissa para a efetivação de um verdadeiro diálogo entre indígenas e nãoindígenas, ou seja, para um diálogo interétnico democrático, simétrico e inteligível para todas as partes envolvidas. A inteligibilidade do diálogo 
parte do entendimento e aceitação entre os participantes sobre termos e regras; e, para que haja simetria no diálogo, é necessário estabelecer um espaço razoavelmente democrático, em que não haja a predominância de um interlocutor sobre outro - a existência de uma autoridade, um interlocutor que exerça poder ou predominância de alguma forma em relação a outro compromete a eticidade do diálogo.

E este é precisamente o desafio ainda não superado em diversos espaços de discussão e tomada de decisão que envolvem indígenas e não-indígenas: romper com a predominância da visão de mundo de determinados interlocutores sobre a visão de mundo de outro e construir diálogos que sejam efetivamente inteligíveis e simétricos. A institucionalização de uso de regras próprias a uma das partes (a parte não-indígena) compromete 0 caráter ético do diálogo intercultural (Cardoso de Oliveira 2000); observa-se que os diálogos interculturais realizados em espaços políticos tidos como oficiais (comunidade nacional e internacional) necessariamente devem estar em conformidade com as regras do discurso não-indígena hegemônico.

A partir do pressuposto empírico de que o diálogo e as decisões ocorrerão em espaços com regras já definidas - as não-indígenas -, os indígenas adotam maneiras para fazer-se ouvir e fazer-se entender nestes espaços. Assim, o que se observa comumente nos diálogos entre indígenas e nãoindígenas está longe de um diálogo interétnico ético: interlocutores indígenas traduzem suas visões de mundo em termos e conceitos que se aproximam de termos e conceitos não-indígenas, para se fazer entender uma vez que a premissa do diálogo não é a construção comum dos termos, e sim os termos utilizados pelos não-indígenas. Diante da dificuldade para construir um diálogo interétnico e ético (nos termos aqui colocados), diversas organizações indígenas e seus representantes buscam maneiras de fazer sua voz ser escutada, com o grande desafio de construir pontes entre visões de mundo bastante distintas.

No final da década de 1980, Davi Kopenawa, xamã Yanomami, ganhou projeção internacional ao defender o direito de seu povo à sua terra, por sua capacidade de sintetizar as ameaças a seu povo junto à enunciação da "natureza indígena conservacionista", no contexto em que os nãoindígenas ao redor do mundo passam a identificar os povos indígenas como "guardiões naturais das florestas" (emergência da agenda ambientalista a nível internacional). Para se comunicar com não-indígenas de maneira que eles entendam e, ao mesmo tempo, apresentar seu ponto de vista a partir da visão de seu povo, Kopenawa utiliza conceitos aproximados e adaptações 
que permitam correspondências entre visões de mundo totalmente diferentes ${ }^{15}$.

Sobre a visibilidade conquistada por Kopenawa e outras lideranças indígenas no cenário internacional, Albert (1995) afirma haver uma "reelaboração cosmológica" que articula nestes discursos categorias indígenas e não-indígenas. A partir de sua convivência com os Yanomami, descreve a trajetória de Kopenawa e a percepção de uma mudança na própria perspectiva Yanomami de ver o mundo, para além de suas enunciações públicas: o 'branco', antes tido como sub-humano, torna-se um ser inteligível, cujas categorias de percepção do mundo são compreendidas e, portanto, utilizadas. Acompanhando essa mudança da visão sobre o 'branco' e suas categorias, vem uma mudança na postura Yanomami em relação a estes, que marca também uma inflexão na forma mesma de se construir a fala e de se posicionar politicamente. Passa-se de posicionamentos marcados por uma 'resistência etnocêntrica' - ou seja, de pautar o discurso sobre a visão próprio do que é o outro (branco) para si (Yanomami) - para posicionamentos marcados por falar do que se é (Yanomami) para o outro (branco), o que Albert (1995) chama de "etnicidade adaptada". Em 1998, povos indígenas da América do Norte se reuniram para discutir mudanças climáticas e lançaram a Declaração de Albuquerque, que fornece um bom exemplo de etnicidade adaptada:

Our prophecies and teachings tell us that life on earth is in danger of coming to an end. We have accepted the responsibility designated by our prophecies to tell the world that we must live in peace and harmony and ensure balance with the rest of Creation. The destruction of the rest of Creation must not be allowed to continue, for if it does, Mother Earth will react in such a way that almost all people will suffer the end of life as we know it.

A growing body of western scientific evidence now suggests what Indigenous Peoples have expressed for a long time: life as we know it is in danger. We can no longer afford to ignore the consequences of this evidence. We must learn to live with this shadow, and always strive towards the light that will restore the natural order. How western science and technology is

\footnotetext{
${ }^{15}$ É o fato de Kopenawa manter em suas falas certas noções centrais para a cosmovisão Yanomami que lhe garante a legitimidade étnica necessária para ser reconhecido enquanto interlocutor indígena autêntico (Mesquita, 2016)
} 
being used needs to be examined in order for Mother Earth to sustain life. (Circles of Wisdom, 1998)

Assim, entende-se o discurso político indígena contemporâneo como constituído a partir da reconstrução simbólica de categorias próprias e externas (a do interlocutor não-indígena) que reconfiguram não apenas o discurso, mas a própria (cosmo)visão e o posicionamento indígena.

\section{A proposta da COICA nos diálogos sobre clima: REDD+ Indígena Amazônico}

"REDD" é sigla para Redução Compensada de Emissões por Desmatamento e Degradação Florestal, um mecanismo de mitigação à mudança do clima discutido desde 2005 nas COP como forma de incentivar financeiramente países em desenvolvimento a preservar suas áreas de floresta. $O$ mecanismo tem como premissa a importância de visibilizar e evitar as emissões de gases de efeito estufa associadas a atividades que resultam em desmatamento e degradação florestal. Entre 2005 e 2010, a proposta de REDD que era discutida a nível internacional teve muitas críticas por parte da sociedade civil, que apontavam para os limites das soluções baseadas na lógica de mercado para as mudanças climáticas, a mercantilização da natureza e para os riscos à autonomia e aos direitos territoriais de povos tradicionais que vivem nas florestas ${ }^{16}$.

Além disso, a sociedade civil organizada apontou para o risco de REDD ter um "efeito perverso" de compensar os que historicamente já haviam desmatado áreas de floresta e deixam de fazê-lo a partir do incentivo financeiro, mas não reconhecer os que sempre mantiveram as florestas em pé. Em 2008, a COICA lança a "Carta de Cuiaba sobre el cambio climático y los pueblos indígenas", em que são apresentadas 21 recomendações para a COP14. As recomendações de número cinco e seis tratam especificamente dos riscos e lacunas de REDD para povos indígenas:

5. Fortalecimiento de los mecanismos que REDD no puede ignorar la autonomia de los pueblos indígenas sobre sus territorios.

6. Nos preocupa que el post-2012 REDD régimen que se está debatiendo en las $C P$ se utiliza para compensar a aquellos que siempre han limpiado nuestros bosques: los principales productores de soja, la ganadería y los biocarburantes y otros. Exigimos que la REDD y otros mecanismos de compensación

\footnotetext{
${ }^{16}$ Para uma discussão mais detalhada sobre as críticas formuladas pela sociedade civil à REDD neste período, ver Mesquita 2016.
} 
para reducir las emisiones de carbono pagar, priorizar $y$ distribuir los benefícios a las personas que conservan el bosque $y$ han resistido a la presión económica para deforestación. (COICA, 2008)

Considerando as críticas e propostas da sociedade civil organizada, na COP16 são estabelecidas diretrizes para reduzir os riscos de impactos negativos de REDD, que ficaram conhecidas como Acordo de Cancun (local onde foi realizada a COP16). Em primeiro lugar, a Decisão 1/CP.16 reconhece como contribuição para mitigação às mudanças do clima não apenas as ações de desmatamento e degradação florestal evitados, como também ações de conservação de estoques de carbono florestal, manejo sustentável de florestas e aumento dos estoques de carbono (UNFCCC, parágrafo 70, Decisão 1/CP.16, 2010) - ações estas que contemplam os que, como os povos indígenas, conservam áreas de floresta.

A inclusão destas ações a REDD resultou no acréscimo do símbolo de "+" à sigla, referida daí em diante como REDD+. Em segundo lugar, na COP16 foram estabelecidas uma série de salvaguardas para a implementação de REDD+, como medidas a serem tomadas pelos governos nacionais para evitar que ações de REDD+ resultem direta ou indiretamente em prejuízos sócio-ambientais. Estas salvaguardas explicitam a obrigação de respeitar os direitos dos povos indígenas, a participação efetiva de povos e comunidades locais na tomada de tais ações e a necessidade de que estas não resultem em deslocamentos de áreas de desmatamento (UNFCCC, Decisão 1/CP.16, Apêndice I, 2010). Foi apenas em 2013, na COP19, que foram estabelecidas regras internacionais para a implementação de REDD+ - em acordo que ficou conhecido como Marco de Varsóvia -, como a abordagem nacional de REDD+ e o pagamento por resultados já alcançados (UNFCCC 2013).

Paralelamente às discussões e definições sobre REDD+ no âmbito das negociações entre países da ONU, configurou-se um mercado de carbono que mobilizou recursos para implementação de ações e projetos dispersos com os mesmos objetivos de REDD+. Enquanto as principais diretrizes para REDD+ não foram definidas (Acordo de Cancun na COP16 - 2010 - e Marco de Varsóvia na COP19 - 2013), houve ações ilícitas e mesmo abusivas associadas à ideia de REDD+: entre 2010 e 2012, a FUNAI foi notificada de cerca de 30 contratos de projetos de carbono que feriam direitos dos povos indígenas ${ }^{17}$.

\footnotetext{
${ }^{17}$ A FUNAI conseguiu invalidar estes contratos legalmente e os assédios de empresas a povos indígenas para assinatura de contratos desse tipo gradualmente cessaram.
} 
Os casos que tiveram mais repercussão foram os contratos dos povos Cinta Larga e Munduruku com a empresa Celestial Green Ventures assinados em 2011, que estipulavam a manutenção da área de floresta das Terras Indígenas intacta por 30 anos, sob pena de multa, e condicionando qualquer intervenção na área à aprovação da empresa ${ }^{18}$. Por cause de contratos como estes, pela falta de definições e de difusão de informação precisa sobre REDD+, este mecanismo foi associado quase que exclusivamente a esse tipo de ação ilícita ou abusiva até 2013 , tornando importante o esclarecimento acerca do mecanismo junto a povos indígenas para o posicionamento de lideranças e organizações.

Atenta à discussão sobre um mecanismo com potencial de trazer riscos e benefícios aos povos indígenas da região, a COICA, que debatia REDD+ desde $2008^{19}$, propôs pela primeira vez na COP17 de 2011 (e depois novamente nos anos seguintes) uma proposta intitulada de "REDD+ Indígena Amazônico". REDD+ Indígena Amazônico (RIA) apresenta uma alternativa ao mecanismo de REDD+ convencional, como forma de propor outro significado de REDD+ nas COP, espaço onde o mecanismo era debatido e construído. $O$ intuito foi o de elaborar uma proposta própria de REDD+ que convergisse com a "agenda permanente dos povos indígenas, condicionando e adaptando [o mecanismo] aos direitos e cosmovisões" (Espinoza 2014) dos povos indígenas, ao invés de tomar um posicionamento favorável ou contrário ao mecanismo de REDD+ tal como esta vinha sendo discutida na UNFCCC.

Assim, RIA sugere adequações ao mecanismo de REDD+ para sua implementação junto aos povos indígenas: a revisão dos formatos de contratos de carbono, a garantia aos direitos dos povos indígenas, uma abordagem mais ampla do território e dos elementos ali presentes (além do carbono), a atenção às ameaças do entorno e a importância da autonomia dos povos indígenas para a manutenção das florestas (COICA 2011). Enquanto REDD+ trata especificamente da redução de emissões de gases de efeito estufa, RIA alia a redução das emissões advindas do desmatamento, degradação florestal e conservação de estoques de carbono à visão e práticas indígenas que são tratadas a um só tempo como estratégias de mitigação e adaptação às mudanças climáticas.

Em consonância com o reconhecimento oficial da autonomia e do conhecimento dos povos indígenas (estabelecidos pelo Acordo de Cancun),

\footnotetext{
${ }^{18}$ Para ler o contrato entre Celestial Green Ventures e o povo Munduruku na íntegra, ver o Anexo III de Mesquita (2016).

${ }^{19}$ Para mais sobre o posicionamento da COICA sobre REDD+ e o histórico da construção da proposta de RIA, ver Mesquita 2016.
} 
RIA pretende visibilizar como os modos de vida, cosmovisão e manejo dos territórios indígenas são em si ações que podem tanto garantir a redução das emissões de gases de efeito estufa mantendo as áreas de floresta, quanto o conhecimento sobre o território possibilita aos povos indígenas estabelecer medidas de adaptação necessárias a alterações climáticas (seja o cultivo de outras plantas pelas circunstâncias que mudam, a adoção de novos hábitos de alimentação ou mesmo migrações quando necessárias).

Acompanhando o desenvolvimento do conceito e das diretrizes de REDD+ nas COP em paralelo às manifestações da COICA sobre REDD+ enunciadas desde 2010, pode-se observar que a COICA influencia e é influenciada pelas negociações e decisões. Se, por um lado, a organização foi um dos sujeitos que influenciou o reconhecimento oficial aos direitos e conhecimento dos povos indígenas para implementação de ações de REDD+ (UNFCCC, Decision 1/CP16, Apendice I, item 2c), as Decisões da COP perpassam os aspectos centrais de RIA, mencionados acima. Há, entretanto, um esforço por parte da COICA em dar mais conteúdo e destaque para estes aspectos referentes aos povos indígenas que, de outra maneira, teriam muito menos visibilidade se circunscritos a algumas entre tantas Definições das COP. Assim, RIA coloca o conhecimento indígena, sua maneira de viver e estar no mundo e sua relação com a terra no centro da proposta para um mecanismo de compensação financeira que prevê o pagamento por resultado (ou seja, o pagamento pela quantificação do carbono não emitido), reivindicando para isto a autonomia dos povos indígenas, a garantia de seus direitos e territórios e a manutenção dos modos de vida tradicionais dos povos indígenas como premissa para qualquer ação de REDD+ relacionada a estes povos.

Se o cerne da questão no mecanismo de REDD+ é garantir a redução das emissões de gases de efeito estufa e a manutenção de estoques de carbono, colocando os benefícios sócio-ambientais advindos destas ações são cobenefícios descritos em segundo plano (na forma de salvaguardas e apêndices), RIA desloca para o ponto central da proposta a integralidade dos territórios que contemple diversos seres vivos. Em sua submissão à COP20 (2014), o documento intitulado "Redd+ mas allá del carbono y del mercado: Integralidad del Redd+ Indígena Amazónico" (COICA 2014), são feitas considerações e recomendações da COICA sobre RIA que se reportam à decisões de COP anteriores e outros tratados internacionais (como a Convenção 169 da OIT), mas todas articuladas em torno da noção de que o manejo dos territórios indígenas e de seus serviços ecossistêmicos de maneira integral é o ponto em torno do qual se pode articular a redução das emissões de gases de efeito estufa, as estratégias de adaptação às 
mudanças do clima, mecanismos de financiamento e benefícios sócio culturais:

El balance de carbono, como capacidad de absorción y almacenaje de carbono, es una función ecosistémica importante, pero inseparable de las demás. La reserva de carbono es indesligable de las capacidades de dispersión de semillas, ambos conectados a formación de suelos, y todos ellos al manejo cultural indígena de la totalidad de las selvas. Implica que no hay absorción de carbono sin cobeneficios, olos demás beneficios múltiples. Y a la inversa también, dichos cobeneficios van siempre acompañados de reservas de carbono. (COICA 2014)

O que a COICA fez ao apresentar uma proposta própria e estruturada de REDD+ em um fórum da ONU é ilustrativo de como a organização foi capaz de se apropriar de um mecanismo inicialmente desvinculado de seus interesses de forma a corroborar suas pautas. Entre 2011-2014, a proposta de RIA desenvolvida e enunciada pela COICA logrou ganhos e potencialidades para o movimento indígena, tais como: fortalecer a garantia dos direitos e o respeito à autonomia e ao conhecimento dos povos indígenas dentro do debate sobre mitigação e adaptação a mudanças climáticas; adequar o mecanismo de REDD+ convencional aos termos propostos por indígenas, ao propor que este mecanismo sirva para fortalecer o manejo territorial de cada povo (por meio da elaboração de Planos de Vida ou Planos de Gestão Territorial); reforçar o protagonismo e incidência de organizações indígenas na agenda climática.

Após as definições para REDD+ estabelecidas pelo Marco de Varsóvia em 2013 , a partir das quais os países em desenvolvimento passam a elaborar Estratégias Nacionais para implementação de REDD+, RIA ganha o potencial de influenciar a elaboração destas Estratégias. No Peru, a atuação conjunta da COICA e da AIDESEP garantiu recursos do Plano de Preparação de REDD+ do Peru e do Forest Investment Program (FIP - fundo multilateral que tem um mecanismo dedicado a povos indígenas) para a titulação de territórios indígenas e para o manejo territorial (Espinoza, 2014).

\section{Conclusão: esforços de tradução - fazer-se entender}

Em um contexto em que ainda se discutia o desenho de um mecanismo de REDD+ (entre 2010 e 2013), a proposta de RIA serviu para atestar o protagonismo dos povos indígenas nas discussões sobre clima. $O$ trabalho feito pela COICA com RIA (e em tantos outros momentos de sua trajetória 
como organização indígena) foi o de construir uma proposta que aliasse o que os interlocutores presentes nas negociações sobre o clima eram capazes de entender e tinham abertura para ouvir às pautas da COICA enquanto organização indígena que defende os direitos dos povos indígenas.

O exercício de tradução e mediação empreendido por lideranças indígenas para a construção de falas nestes espaços nacionais e internacionais de tomada de decisão (como as $\mathrm{COP}$ ) vai se aprimorando à medida em que estes enunciadores adquirem experiência e aprendizado sobre o que os não-indígenas querem ouvir, do que resultam importantes "ajustes" no discurso - que muitas vezes são a diferença entre propostas e discursos que ganham projeção ou não. Considerando a impossibilidade de se travar um diálogo interétnico ético e simétrico, conforme exposto acima, o trabalho de construção de pontes entre as agendas garante que a fala de uma liderança indígena seja apreendida por interlocutores não-indígenas: sua capacidade de comunicar ao espectador uma combinação entre o que o enunciador disse e aquilo que o espectador espera ouvir, utilizando para isto uma mescla da linguagem corrente nas negociações do clima (os termos técnicos e a lógica a eles subjacente, como REDD+, desmatamento evitado e redução de gases de efeito estufa) e da linguagem das organizações indígenas (as reivindicações por terra, autonomia e reconhecimento).

RIA é um exemplo desse trabalho de tradução, situado em um momento em que o próprio REDD+ estava em construção - ou seja, ainda em disputa. Foi possível à COICA incluir nas negociações sua visão sobre o mecanismo a partir da criação de um conceito próprio (RIA) que passa a ser reconhecido e diferenciado - não REDD+, mas REDD+ Indígena. Na medida em que estas categorias são transformadas e dão origem a conceitos adaptados, observase a modificação operada não só no campo simbólico indígena como no não-indígena, possibilitando influência e incorporação de visões diversas. Portanto, para os povos indígenas, dominar a linguagem do não-indígena significa aproximar as posições destes sujeitos no diálogo interétnico, diminuindo a assimetria imposta pelas regras colocadas para este diálogo.

Nesse sentido, "falar a língua do outro" - não dominando apenas o idioma, como também os conceitos e racionalidade que os perpassam - é, além de um recurso político, a forma que mais se aproxima para alcançar um diálogo real que possibilite a inteligibilidade do enunciado pelas partes envolvidas. Considerando que o discurso político indígena tem como interlocutor o(s) não-indígena(s) e que os espaços em que se dão os diálogos entre indígenas e não-indígenas não possibilitam condições para 0 
estabelecimento de diálogos interétnicos simétricos, a combinação entre categorias indígenas e não-indígenas é o que garante a própria viabilidade política do discurso, por construir inteligibilidade tanto para conceitos nãoindígenas quanto para a apresentação da visão indígena sobre os temas tratados. Sem essa combinação de categorias, que reflete a habilidade do enunciador indígena em traduzir e mediar em sua fala visões de mundo distintas, o discurso político indígena estaria fadado ao fracasso (Albert 1995) - seja pela inabilidade de conseguir estabelecer comunicação com "o outro" por utilizar apenas conceitos próprios, seja pela ausência de conceitos próprios que possam fazer perceber a importância da reivindicação própria dos povos indígenas ou de determinado grupo étnico.

\section{Referências Bibliográficas}

ALBERT, Bruce. "O ouro canibal e a queda do céu: uma crítica xamânica da economia política da natureza”. Série Antropologia, n. 174, pp. 1-33, 1995.

BANIWA, Gersem L. "Movimentos e políticas indígenas no Brasil contemporáneo". Tellus, Ano 7, n.12, pp. 127-146, 2007.

BELLO, Álvaro. Etnicidad y ciudadanía en América Latina - La acción colectiva de los pueblos indígenas. Santiago de Chile: CEPAL, 2004.

BRYSK, Alison. "Turning weakness into strength: the internationalization of Indian rights". Latin American Perspectives, 23(2); pp. 38-57, 1996.

BONFIL BATALLA, Guillermo. "El concepto de indio en América: una categoría de la situación colonial". Anales de Antropología, vol. IX. México: UNAM, 1972, pp. 105-124.

CARDOSO DE OLIVEIRA, Roberto. Identidade, Etnia e Estrutura Social. São Paulo: Pioneira, 1976.

CARDOSO DE OLIVEIRA, Roberto. "Ação indigenista, eticidade e o diálogo interétnico". Estudos Avançados, v. 14, n. 40, pp. 213-230, 2000.

CIRCLES OF WISDOM/ NATIVE PEOPLES - NATIVE HOMELANDS CLIMATE CHANGE WORKSHOP. The Albuquerque Declaration. Estados Unidos, Albuquerque. 8 pgs. 1998.

COICA (Coordinadora de las Organizaciones Indígenas de la Cuenca Amazónica). Carta de Cuiaba sobre el cambio climático y los pueblos indígenas. Cuiabá. 4 pgs. 2008. 
COICA (Coordinadora de las Organizaciones Indígenas de la Cuenca Amazónica). Redd+ indígena - gestión holística de Territorios de Vida Plena. Folder, 6 pgs. 2011.

COICA (Coordinadora de las Organizaciones Indígenas de la Cuenca Amazónica). Redd+ más allá del carbono y del mercado: integralidade del Redd+Indígena Amazónico. Submissão da COICA à COP20. 5 pgs. 2014

DE LA CADENA, Marisol; LEGOAS, Jorge. "Cosmopolítica nos Andes e na Amazônia: como políticas indígenas afetam a política?". Interethnic@ Revista de Estudos em Relações Interétnicas, v. 18, n. 1, 2014.

ESPINOZA, Roberto. "Redd+ Indígena Amazónico: Logros, Avances y Desafíos". In: LÓPEZ, Vladimir; MOLERO MESÍA, María. REDD+ Indígena en el Perú: Perspectivas, avances, negociaciones y desafios desde la mirada de los actores involucrados. Lima: GIZ, 2014, pp. 76-81.

GRAHAM, Laura. "How Should an Indian Speak? Amazonian Indians and the Symbolic Politics of Language in the Global Public Sphere". In: WARREN, Kay; JACKSON, Jean (eds). Indigenous Movements, Self-Representation, and the State in Latin America. Austin: University of Texas Press, 2002, pp. 181-227.

GREENE, SHANE. "¿Pueblos Indígenas S. A.? La cultura como política y propiedad en la bioprospección farmacêutica". Rev. colomb. antropol., v. 42, pp. 179-221, Dec. 2006.

IPCC (INTERGOVERNMENTAL PANEL ON CLIMATE CHANGE). Climate change 2007: The physical science basis. Contribution of working group I to the fourth assessment report of the Intergovernmental Panel on Climate Change. Cambridge: Cambridge University Press, 2007.

MEADOWS, D. et al. Os limites do crescimento. São Paulo: Perspectiva, 1972.

MESQUITA, Isabel Rodrigues de. REDD+ indígena amazônico e as dinâmicas de atuação política de uma organização indígena. Dissertação de mestrado, Universidade de Brasília, 2016.

NIEZEN, Ronald. The origins of indigenism: human rights and the politics of identity. Berkeley: University of California Press, 2003.

ONU (ORGANIZAÇÃO DAS NAÇÕES UNIDAS). Convenção-Quadro das Nações Unidas sobre Mudança de Clima. Nova Iorque, 1992. Traduzida por: MINISTÉRIO DA CIÊNCIA E TECNOLOGIA. Brasília: Governo Federal.

POWLESS, Ben. "An Indigenous Movement to Confront Climate Change". Globalizations, Vol. 9, n. 3, pp. 411-424, 2012. 
SMITH, Richard C. "La política de la diversidad. COICA y las federaciones étnicas de la Amazonia”. In: VARESE, Stefano (ed.). Pueblos Indios, Soberanía y Globalismo. Quito: Abya-Yala, 1996, pp. 81-127.

ULLOA, Astrid. La construcción del nativo ecológico. Bogotá: Instituto Colombiano de Antropología e Historia, 2004.

UNFCCC (United Nations Framework Convention on Climate Change). COP 16 Decision 1/CP.16 - Report of the Conference of the Parties on its sixteenth session. Cancun, 2010.

UNFCCC (United Nations Framework Convention on Climate Change). COP 19 Warsaw Framework for REDD-plus. Varsóvia, 2013.

VALENTE, Renata C. A GTZ no Brasil: uma etnografia da cooperação alemã para o desenvolvimento. Rio de Janeiro: UFRJ/Laced, 2010. 